\title{
Cadmium Induced Adverse Effects on Fry of Oreochromis mossambicus
}

\author{
R. A. A. R. Ranatunge, M. R. Wijesinghe* and W. D. Ratnasooriya. \\ Department of Zoology, University of Colombo, Colombo 03.
}

Date Received: 08-04-2011 Date Accepted: 28-09-2011

\begin{abstract}
This study investigates the effects of Cadmium (Cd) on fry of the Mozambique Tilapia Oreochromis mossambicus using standard toxicity tests. Fry were repeatedly exposed to five concentrations $(0.002-$ $2.0 \mathrm{mgl}-1$ ) of $\mathrm{Cd}$ and survival, growth and swimming activity were monitored over 10 days. These trials revealed that all the tested concentrations significantly enhanced mortality of the fry with concentrations above $1.0 \mathrm{mgl}-1$ resulting in $100 \%$ mortality. Mortality was positively related to the exposure level indicating dose-dependency. The LC50 1-10days ranged from 0.02 to $7.26 \mathrm{mgl}-1$. Fry exposed to Cd also exhibited an increase in swimming activity in comparison to those that were not exposed indicating abnormal behaviour. Nevertheless, there was no apparent growth retardation and gross morphological defects during the brief exposure period. These findings are significant because the lethal and sublethal effects in fry were also apparent at Cd concentrations of $0.001-0.2 \mathrm{mgl}-1$, which are typically recorded in fresh waterbodies in Sri Lanka.

Keywords: Cadmium, Oreochromis mossambicus, survival, toxicity, Sri Lanka
\end{abstract}

*Correspondence: E-mail-mayuri@zoology.cmb.ac.lk

Tel-+94071 446277

ISSN 2235-9370 Print/ ISSN 2235-9362 Online (02011University of Sri Jayewardenepura 


\section{Introduction}

Pollution of freshwater bodies is an issue that is being addressed extensively throughout the globe, heavy metals being one of the identified causes (Shazili et al, 2006). The heavy metal Cadmium (Cd) assumes particular importance since it has been shown to reach undesirable levels in freshwater ecosystems such as reservoirs, streams and wetlands in many parts of the world. For instance, Saeed and Shaker (2008) has recorded high levels of Cd in water and sediment in Nothern Delta Lakes, Egypt, while similarly high levels have been recorded by Harikumar et al (2009) in wetland ecosystems in Vembanad, India. As is the case elsewhere, in Sri Lanka too $\mathrm{Cd}$ has become a frequent pollutant. Bandara et al (2008) revealed that high Cd concentrations were recorded in water and sediment in many of the cascade irrigation systems in Sri Lanka. Anthropogenic activities such as metal production, the Nickel-Cadmium battery industry, electroplating and phosphorus fertilizer used in agriculture are responsible for the release of Cd to the natural environment (Kneip and Hazen, 1979; Yilmaz, 2009).

Cd contamination in fresh water is particularly alarming because it is known to be highly toxic to the exposed organisms leading to lethal and sublethal damage. Cd causes direct morality in fish and other aquatic fauna (Brown et al, 1994; Irwin et al, 1997; Joel and Amajuoyi, 2009), reduces hatching rates (Lugowska, 2007), retards growth and development (Sharma and Patino, 2009) and causes deformities and behavioural abnormalities. Cd is known to disrupt physiological and biochemical processes in fish and amphibians (Sehgal and Saxena, 1987; Zhang et al., 2007). Cd also accumulates in organs and tissues (Zyadah and Baky, 2000; Yilmaz, 2009) and therefore often results in biomagnification (Dallinger et al., 1987).

Thus, assessing the toxicity of $\mathrm{Cd}$ on aquatic fauna is of particular importance for Sri Lanka which supports many species of indigenous and endemic aquatic fauna. In the present study we investigate the impact of $\mathrm{Cd}$ on the survival, growth and swimming activity of the fry of the Mozambique Tilapia Oreochromis mossambicus. Studies that assess the toxicity of heavy metals are important for a developing country such as Sri Lanka where water pollution has currently become a national issue. Tilapia was selected as the study species because of its known tolerance to environmental stresses, availability as an aquarium species and the ease of rearing. The toxicity levels exhibited by this will enable us to predict hazards posed to other more sensitive species. Toxicity will be assessed using three end points, i.e. mortality, growth and swimming activity.

\section{Materials and Methodology}

\subsection{Collection of larvae}

Fry aged two weeks were obtained from the National Aquaculture Development Authority, Sri Lanka located in Dambulla. The collection of the fish from these breeding sites ensured that the experimental animals were free from exposure to heavy metals.

\subsection{Selection and preparation of test concentrations of $C d$}

The selection of the test concentrations were based on two factors. The field levels of $\mathrm{Cd}$ in the water bodies of Sri Lanka was considered to be of primary importance since this would reflect the 
general levels that aquatic organisms are exposed to in the long run. However, since the present study involved empirical trials, it was also considered necessary to consider levels and durations of exposure used in previous exposure trials. Accordingly, five test concentrations of Cd, i.e $0.002,0.02,0.2,1$ and $2 \mathrm{mgl}^{-1}$ were selected. Although much higher levels have been previously tested on fish (e.g. Svecevieius, 2007), we considered it more relevant to ascertain effects induced by low Cd concentrations since it better simulates field conditions.

Cadmium chloride $\left(\mathrm{CdCl}_{2}\right)$ was used in the present study following previous exposure experiments by Garcia et al. (1999), Sarnowski and Witeska (2008), and Vinodhini and Narayanan (2008). Hydrated cadmium chloride with the formula of $\mathrm{CdCl}_{2} \cdot 2.5 \mathrm{H}_{2} \mathrm{O}=228.34$ [BDH laboratory reagents (99\% purity), Poole, England] was used to prepare a stock solution with distilled water. Appropriate volumes of the stock solution were then used to prepare the required test concentrations.

\subsection{Experimental set up}

Glass tanks of $22 \times 15 \times 15 \mathrm{~cm}$ size containing $2 \mathrm{~L}$ of tap water were used for the exposure trials. Tap water was aged for 24 hours prior to filling the tanks to allow for the dissipation of chlorine. Different volumes of the $\mathrm{CdCl}_{2}$ stock solution was then added to each tank to obtain the relevant concentrations and mixed well using a glass rod to ensure homogeneity. Each of the treatments and control (without the heavy metal) were maintained in triplicate.

Subsequently, 18 fry of $O$. mossambicus were randomly assigned to control or treatment tanks. Standard body lengths of the fry were measured before they were placed in the tanks. The fry were taken on to a petri dish one at a time with a few drops of water and measured within about 30 seconds using a digital vernier caliper (COMECTA, Electronic digital vernier caliper, Barcelona, Spain).

The fry were fed daily with commercially available fish food pellets (San Aquarium, Colombo). The amounts of food added were determined by preliminary observations. An equal amount of the food was initially added to each tank (fifteen pellets: $30 \pm 1 \mathrm{mg}, \mathrm{n}=10$ ) but this was increased (to thirty pellets: $58 \pm 0.9 \mathrm{mg}, \mathrm{n}=10$ ) as fry grew. In subsequent additions, allowances were made for mortality with the amount of food being determined by the number of live individuals in each tank on a given day. The tanks were kept at room temperature $\left(27.4 \pm 0.04^{\circ} \mathrm{C}\right)$ and exposed to the natural photoperiod of 12 hr light: $12 \mathrm{hr}$ darkness. Exposure trails were conducted for a period of ten days with $\mathrm{Cd}$ concentrations being renewed every other day following modifications of the methods used by Garcia et al. (1999), AlAttar (2005) and Alwan et al. (2009).

All tanks were aerated with a constant flow rate ensuring a continuous supply of oxygen for the fish throughout the trial. Light intensity (LI-250A light meter, Biosciences, Nebraska, USA), pH, temperature ( HANNA, Woonsocket, USA) and dissolved oxygen levels (HANNA HI 9142, Cluj-Napoca, Romania) of the tanks were measured every other day following water renewal.

\subsection{Monitored endpoints}

Mortality of the fry was monitored daily. Readings were taken at the same time on each day between $0900-1000 \mathrm{hrs}$. The dead fry were removed from the tanks. The surviving fry were closely observed to detect morphological aberrations such as tail curvatures or behavioural abnormalities such as alteration 
in speed of swimming, spinning and orientation. The initial (before exposure) and final (on day 10) body lengths were measured to monitor growth. The activity of fry was measured using a specific experimental set up used by Sumanadasa et al., 2008, to record swimming activity. Here the swimming activity of the fry was assessed using the number of crossings per animal in each tank. Activity was recorded every other day (i.e. on days 2, 4, 6, 8 and 10) between 0830 to $1030 \mathrm{hrs}$.

\section{Results}

\subsection{Effect on Mortality}

Overall the results show that the Tilapia fry suffered high levels of mortality due to the exposure to Cd. Mortality at concentrations of $0.002 \mathrm{mgl}-1$ and above were significantly higher than that of the control (one-way ANOVA and post hoc tests: F5,12 $=65.39, p<0.05$ ). At the end of the 10 day exposure the fish in the two highest concentrations ( 1.0 and $2.0 \mathrm{mgl}-1$ ) suffered $100 \%$ mortality (Figure 1). Fry in control tanks also suffered $20 \%$ mortality. Mortality was positively correlated with concentration indicating a significant dose-dependent response (Pearson's correlation $\mathrm{r}=0.672, p<0.005$ ). The $\mathrm{LC}_{50}$ values obtained for Tilapia fry over the 10 days were highly variable and ranged from 0.02 to $7.26 \mathrm{mgl}-$ 1. The $\mathrm{LC}_{50}$ values for 24, 48 and $96 \mathrm{hrs}$ (standard) and 8 and 10 days were 7.26, 3.22, 0.09, 0.03 and $0.02 \mathrm{mgl}-1$ respectively. There was also a difference in the patterns of mortality over time i.e. the peak morality levels at the five concentrations occurred at different durations (two-way ANOVA time * concentration; $\mathrm{F} 45,120=2.76, p<0.05$ ). Interestingly, there were no gross morphological aberrations in any of the Cd treated fry and control fry.

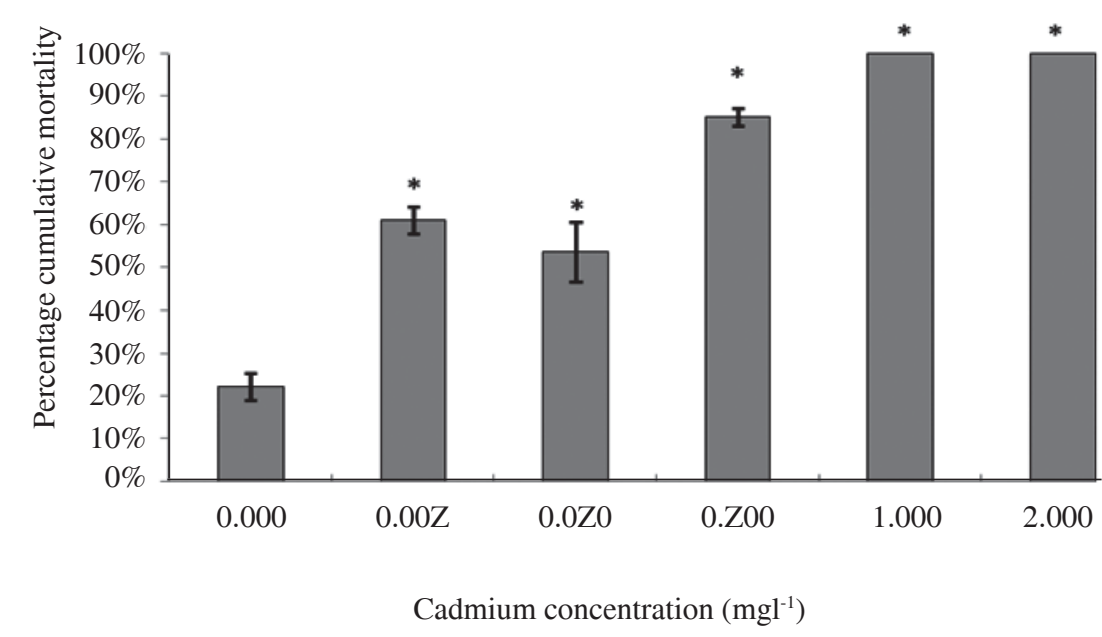

Note: Means are from the three replicates. ${ }^{*}$ Indicates where mortaltty was significantly different from control $(p<0.05)$

Figure 1: Cumulative mortality ( \pm S.E.) of O. mossambicus fry, exposed to five concentrations of Cd during a 10 day repeated exposure trial. 


\subsection{Effect on larval growth}

The present study showed that exposure to the tested concentrations of $\mathrm{Cd}\left(0.002-2.0 \mathrm{mgl}^{-1}\right) \mathrm{did}$ not significantly affect the growth of $O$. mossambicus fry over a ten day period (Table 1 ). The one-way ANOVA confirmed that there was no significant difference in the initial or final lengths of fry between the control and treatment tanks (one-way ANOVA: Initial length $\mathrm{F}_{5,318}=0.07, p>0.05$; Final length $\mathrm{F}_{3,91}$ $=0.95, p>0.05$ ). Growth impairments in larvae exposed to the two highest concentrations (1.0 and 2.0 $\mathrm{mgl}^{-1}$ ) could not be recorded due to $100 \%$ mortality.

Table 1: Mean body lengths ( \pm S.E.) of $O$. mossambicus fry repeatedly exposed to five concentrations of Cd over a period of 10 days.

\begin{tabular}{lcccccc}
\hline & \multicolumn{5}{c}{ Concentration $\left(\mathrm{mgl}^{-1}\right)$} \\
\cline { 2 - 7 } & 0 & 0.002 & 0.02 & 0.2 & 1 & 2 \\
\hline Initial body & 9.80 & 10.31 & 10.14 & 10.35 & 9.83 & 10.28 \\
length (mm) & \pm 0.13 & \pm 0.18 & \pm 0.20 & \pm 0.18 & \pm 0.15 & \pm 0.17 \\
& $(\mathrm{n}=54)$ & $(\mathrm{n}=54)$ & $(\mathrm{n}=54)$ & $(\mathrm{n}=54)$ & $(\mathrm{n}=54)$ & $(\mathrm{n}=54)$ \\
Final body & 10.78 & 10.85 & 10.54 & 9.95 & - & - \\
length (mm) & \pm 0.21 & \pm 0.36 & \pm 0.28 & \pm 0.40 & & \\
& $(\mathrm{n}=41)$ & $(\mathrm{n}=21)$ & $(\mathrm{n}=25)$ & $(\mathrm{n}=8)$ & - & - \\
\hline
\end{tabular}

\subsection{Effect on larval activity}

Unlike in the case of growth, exposure to $\mathrm{Cd}$ altered the swimming activity of $O$. mossambicus fry to some extent. A two way ANOVA confirmed that there was a significant enhancement in activity levels over time across the different treatments and control (two-way ANOVA: time $*$ concentration; $\mathrm{F}_{12.40}=$ $32.49, p<0.05)$. The fry that were not exposed showed a near constant and low rate of activity throughout the trial as indicated by the mean number of crossings per individual (Figure 2). Further, none of the $\mathrm{Cd}$ treated fry exhibited spinning and alteration in orientation.

\section{Discussion}

The present study has shown that $\mathrm{Cd}$ induces lethal and sub lethal toxicity in fry of the Mozambique Tilapia Oreochromis mossambicus. This was apparent for two end points mortality and activity, but was not obvious for the third end point, growth. These results are particularly noteworthy given that the environmentally relevant levels of $\mathrm{Cd}$ are capable of inducing high levels of mortality in fry of the tested species. In fact a concentration of $1.0 \mathrm{mgl}-1$ and above was capable of causing $100 \%$ mortality of the fry, at least under empirical conditions. The findings of the present study are in agreement with those of others on amphibians and fish. For instance, in a similar study with Cnesterodon decemmaculatus fry, Cd concentrations of 0.05 and $0.1 \mathrm{mgl}-1$ respectively induced $86 \%$ and $96 \%$ mortality as a result of a seven day exposure to $\mathrm{Cd}$ (Garcia et al., 1999). As observed in the present study many authors have shown that heavy metal-induced mortality is also dose-dependent (e.g. Heath, 1995; Garcia et al., 1999). 


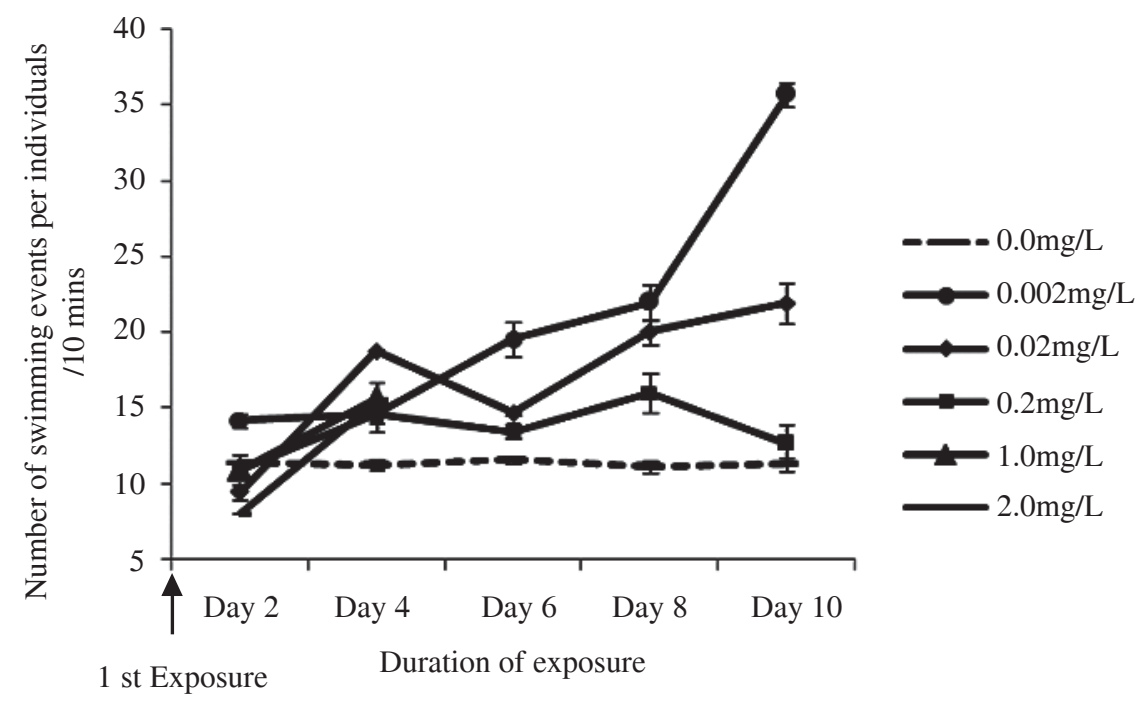

Figure 2: Effect of Cd on swimming activity (mean number of crossings) of O. mossambicus fry repeatedly exposed to five different concentrations of $\mathrm{Cd}$ during a ten day period. Note: Values show mean number of crossings per individual for 10 minutes.

The $\mathrm{LC}_{50}$ values in the present study were similar to those recorded in other studies. For instance, the 96h LC $\mathrm{LC}_{50}$ of O. mossambicus was $0.05 \mathrm{mgl}-1$ (Formicki et al., 2008) while a value of $0.09 \mathrm{mgl}-1$ was recorded in the present study.

In fish, gills are the primary site of damage when exposed to high concentrations of $\mathrm{Cd}$ over a short period. Chung, 1983 has reported that respiratory failure and suffocation occurs due to the deposition of dead cellular material on gill surfaces. Histopathological studies have confirmed this in the fresh water fish Macropsobrycon uruguayanae exposed to $1.5 \mathrm{mgl}^{-1}$ of Cd for 15 days (Randi et al., 1996). Ionic imbalances have been recorded by Heath (1995) which might have also contributed to the observed mortality in the fry. With regard to dose-dependency, a progressive decrease in plasma $\mathrm{Na}$ has been shown to occur in Tilapia exposed to Cd (Heath, 1995) which most likely induces dose-dependent mortality as that observed in the present study. Since $\mathrm{Cd}$ has the potential to accumulate within organs (e.g. Nebeker et al., 1995) this factor might also trigger mortality at relatively high concentrations or over a relatively long exposure period. Accumulation rates might be partly responsible for the variation in mortality rates in different concentrations of the heavy metal, with time. Fry exposed to the two highest concentrations ( 1 and $2 \mathrm{mgl}^{-1}$ ) suffered instant mortality, i.e within $24 \mathrm{hrs}$, while mortality was delayed in those exposed to lower concentrations probably because accumulation to lethal levels take longer.

As opposed to mortality, Cd exposure had no apparent effect on growth of $O$. mossambicus fry. In the case of Tilapia growth impairments may not be very evident considering the brief period over which the trial was conducted. In fact other studies on fish conducted over a longer duration have shown that $\mathrm{Cd}$ has the potential to cause growth reductions in fish. Sarnowski and Witeska (2008) demonstrated 
that larvae of Cyprinus carpio L. which were exposed to $0.2 \mathrm{mgl}^{-1}$ of $\mathrm{CdCl}_{2}$ and monitored for 30 days were shorter compared to those of the control. In another study, Shalaby (2007) has shown that 10 $\mathrm{mgl}^{-1}$ of Cd induced growth retardation was observed in a 45 days trail with $O$. niloticus.

With regard to alteration in activity levels by $\mathrm{Cd}$ in the present study, all tested concentrations of Cd induced hyperactive behaviour or accelerated swimming activity in the fry. Such observations have also been made by Giusi et al. (2005) for Thalassoma pavo with Cd exposure. It has been shown that $3 \mathrm{mgl}^{-}$ ${ }^{1}$ of $\mathrm{Cd}$ induces elevations in blood glucose levels in O. nilloticus (Al-Attar, 2005) most likely resulting in hyperactive behaviour. The brain has been identified as one of the target organs for $\mathrm{Cd}$ in vertebrates (Minami et al., 2001). Thus it is possible that Cd may have stimulated the cerebellum, which is responsible for the coordination of skeletal muscle movements (Ganong, 1983).

\section{Conclusion}

The present study highlights the fact that $\mathrm{Cd}$ at environmentally relevant concentrations of $0.02-$ $0.20 \mathrm{mgl}-1$ has the potential to induce lethal and sublethal damage in fry of Oreochromis mossambicus. This is particularly significant because the Tilapia is considered to be a relatively hardy species. In the light of these findings it is necessary to strongly emphasize the need to have stringent measures for the discharge of contaminated effluents, from industries in particular, to the inland freshwater bodies of Sri Lanka so as to ensure that the concentrations of these harmful substances do not reach undesirable levels.

\section{Acknowledgement}

We are grateful to the University of Colombo for providing funds and facilities. We particularly acknowledge Mr. J. R. A. C. Jayakody and Mrs. N. S. Abeysinghe for their technical assistance.

\section{References}

Al-Attar, A. M., 2005. Biochemical effects of short-term Cd exposure on the freshwater Fish, Oreochromis niloticus. Journal of Biological Sciences, 5(3), 260-265.

Alwan, S. F., Hadi, A. A. and Shokr, A. E., 2009. Alterations in hematological parameters of fresh water fish, Tilapia zillii, exposed to Aluminium. Journal of Science and Its Applications, 3(1), 12-19.

Bandara, J. M. R. S., Senevirathna, D.M.A.N., Dasanayake, D.M.R.S.B., Herath, V., Bandara, J.M.R.P., Abeysekara, T. and Rajapaksha, K.H., 2008. Chronic renal failure among farm families in cascade irrigation systems in Sri Lanka associated with elevated dietary cadmium levels in rice and freshwater fish (Tilapia). Environmental Geochemistry and Health, 30(5), 465-478.

Brown, V., Shurben, D., Miller, W. and Crane, M., 1994. Cadmium toxicity to rainbow trout Oncorhynchus mykiss walbaum and brown trout Salmo trutta L. over extended exposure periods. Ecotoxicology and Environmental Safety, 29(1), 38-46.

Chung, K. S. 1983. Lethal effects of cadmium in tropical fishes. Bulletin of the Japanese Society of Scientific Fisheries, 49(10), 1565-1568. 
Dallinger, R., Prosi, F., Segner, H. and Back, H. 1987. Contaminated food and uptake of heavy metals by fish: a review and a proposal for further research. Oecologia, 73(1), 91-98.

Formicki, G., Stawarz, R., Lukac, N., Putala, A. and Kuczkowska, A., 2008. Combined effects of cadmium and ultraviolet radiation on mortality and mineral content in common frog (Rana temporaria) larvae. Journal of Environmental Science and Health Part A, 43, 1174-1183.

Ganong, W. F., 1983. Review of Medical Physiology. 11 ${ }^{\text {th }}$ edition. Lange Medical Publications, Los Altos, California.

Garcia, M. E., Cappelletti, C. A. and Salibian, A., 1999. Sublethal maternal pre-exposure of fish to cadmium. Effect on the survival of the newly hatched alevins. Archives of Physiology and Biochemistry, 107(2), 152-158.

Giusi, G., Facciolo, R. M., Alo, R., Carelli, A., Madeo, M., Brandmayr, P. and Canonaco, M., 2005. Some environmental contaminants influence motor and feeding behaviors in the ornate wrasse (Thalassoma pavo) via distinct cerebral histamine receptor subtypes. Environmental Health Perspectives, 113(11), 1522-1529.

Harikumar, P. S., Nasir, U. P. and Mujeebu Rahman, M. P., 2009. Distribution of heavy metals in the core sediments of a tropical wetland system. International Journal of Environmental Science and Technology, 6(2), 225-232.

Heath, A. G. 1995. Water pollution and fish physiology. Lewis Publishers, Florida.

Irwin, R. J., Mouwerik, M. V., Stevens, L., Seese, M. D. and Basham, W., 1997. Environmental contaminants encyclopedia - Cadmium entry. National Park Service, Fort Collins, Colorado.

Joel, O.F., Amajuoyi, C.A. 2009. Evaluation of the Effect of Short-Term Cadmium Exposure on Brackish Water Shrimp-Palaemonetes africanus. Journal of Appied. Scences and Environmental Management, 13(4), $23-27$.

Kneip, T. J. and Hazen, R. E., 1979. Deposit and mobility of cadmium in a marsh-cove ecosystem and the relation to cadmium concentration in biota. Environmental Health Perspectives, 28, 67-73

Lugowska, K. 2007. The effect of Cadmium and Cadmium/Copper mixture during the embryonic development of Common Carp larvae, Electronic Journal of Ichthyology, 2, 46-60.

Minami, A., Takeda, A., Nishibaba, D., Takefuta, S. and Oku, N., 2001. Cadmium action in synapses in the brain. Riken Review, 35

Nebeker, A. V., Schuytema, G. S. and Ott, S. L. 1995. Effects of cadmium on growth and bioaccumulation in the northwestern salamander Ambystoma gracile. Archive of Environmental Contamination and Toxicology, 29, 492-499.

Randi, A. S., Monserrat, J. M., Rodriguez, E. M. and Romano, L. A., 1996. Histopathologieal effects of cadmium on the gills of the freshwater fish, Macropsobrycon uruguayanae Eigenmann (Pisces, Atherinidae). Journal of Fish Diseases, 19, 311-322.

Saeed, S.M., Shaker, I.M. 2008. Assessment of heavy metals pollution in water and sediments and their effect on Oreochromis niloticus in the Northern Delta Lakes, Egypt, 8th International Symposium on Tilapia in Aquaculture 2008.

Sarnowski, P. and Witeska, M., 2008). The effects of copper and cadmium in single exposure or coexposure on growth of Common Carp (Cyprinus Carpio L.) Larvae. Polish Journal of Environmental Studies, 17(5), 791-796. 
Shalaby, A. M. E., 2007. Effect of EDTA on toxicity reduction of cadmium in relation to growth, some haematological and biochemical profiles of Nile Tilapia (Oreochromis niloticus). Journal of Fisheries and Aquatic Science, 2(2), 100-109.

Sehgal, R. and Saxena, A. B. 1987. Determination of acute toxicity levels of cadmium and lead to the fish Lebistus reticulates. International Journal of Environmental Studies, 29(2\&3), 157-161.

Shazili, N.A.M., Yunus, K., Ahmad, A.S., Abdullah, N. Rashid, M.K.A. 2006, Heavy metal pollution status in the Malaysian aquatic environment, Aquatic Ecosystem Health \& Management, 9(2), 137 $-145$

Sharma, B. and Patino, R., 2009. Effects of cadmium on growth, metamorphosis and gonadal sex differentiation in tadpoles of the African clawed frog, Xenopus laevis, Chemosphere, 76(8), 10481055 .

Sumanadasa, D. M., Wijesinghe, M. R. and Ratnasooriya, W. D. 2008. Effects of Diazonian on larvae of the Asian common toad (B. melanostictus, Schneider 1799). Environmental Toxicology and Chemistry, 27(11), 2320-2325.

Svecevieius, G., 2007. The use of fish avoidance response in identifying sublethal toxicity of heavy metals and their mixtures. Acta Zoologica Lituanica, 17(2), 139-142.

Vinodhini, R. and Narayanan, M., 2008. Bioaccumulation of heavy metals in organs of fresh water fish Cyprinus carpio (Common carp). International Journal of Environmental Science and Technology, 5(2), 179-182.

Yilmaz, F., 2009. The comparison of heavy metal contaminations (Cd, Cu, Mn, $\mathrm{Pb}$ and $\mathrm{Zn}$ ) in tissues of three economically important fish (Anguilla anguilla, Mugli cephalus and Oreochromis niloticus) inhabiting Koycegiz Lake - Mugla (Turkey). Turkish Journal of Science \& Technology, 4(1), 7-15.

Zhang, Y., Huang, D., Zhao, D., Long, J., Song, G. and Li, A., 2007. Long-term toxicity effects of cadmium and lead on Bufo raddei Tadpoles. Bulletin of Environmental Contamination and Toxicology, 79, 178-183.

Zyadah, M.A., Baky, T.E.A., 2000. Toxicity and Bioaccumulation of Copper, Zinc, and Cadmium in Some Aquatic Organisms, Bulletin of Environment Contamination and Toxicology, 64:740-747. 